\title{
PENGENALAN COASTAL CLEAN-UP DI KAWASAN EKOWISATA PULAU DERAWAN, KABUPATEN BERAU, KALIMANTAN TIMUR
}

\author{
Introduction To Coastal Clean-Up In The Area Of Ecotourism Derawan Island, Berau Regency, \\ East Borneo
}

\author{
Zainuddin $^{1}$, Gazali Salim ${ }^{2}$ \\ ${ }^{1,2}$ Faculty of Fisheries and Marine Science.Borneo Tarakan University 77111, Indonesia. \\ ${ }^{*}$ Corresponding author : Tel: +6285246370028 \\ *Email Korespondensi : zainuddin0713@gmail.com
}

\begin{abstract}
ABSTRAK
Pulau Derawan memiliki habitat sesuai ecological preference salah satunya adalah kawasan Wisata Pulau Derawan. Yang terletak di Kecamatan Pulauan Derawan, Kabupaten Berau, Provinsi Kalimantan Timur. Besarnya potensi sumberdaya hayati laut yang tinggi harus di imbangi dengan melindungi habitat ekosistem biota tersebut terutama di Ekowisata Pulau Derawan. Perlindungan habitat sangat penting bagi kelangsungan hidup biota laut sehingga biota laut sangat perlu dijaga kelestariannya dalam hal bersih-bersih di kawan Pulau Derawan. Bersih-bersih pantai atau Coastal Clean-up merupakan kegiatan internasioal yang di kembangkan di daerah pantai untuk keberlangsungan dan perlindungan ekosistem. Kegiatan coastal clean-up telah dilaksanakan di daerah ekowisata Pulau Derawan didapatkan 3 jenis sampah yaitu dari rumah tangga, sampah dari alam dan sampah wisatawan. Total keseluruhan sebanyak $157 \mathrm{~kg}$ dengan komposisi distribusi jenis sampah berasal dari wisatawan sebesar $2 \mathrm{~kg}$ dengan persentase sebesar $1 \%$ kemudian distribusi jenis sampah berasal dari alam sebesar $60 \mathrm{~kg}$ dengan persentase sebesar $38 \%$ kemudian distribusi jenis sampah berasal dari warga/rumah tangga sebesar $95 \mathrm{~kg}$ dengan persentase sebesar $61 \%$.
\end{abstract}

Kata kunci : Coastal Clean-Up, Sampah, Pulau Derawan, Kalimantan Timur

\begin{abstract}
Derawan has appropriate ecological habitat preference, one of which is the tourist area Derawan. Located in Kecamatan Pulauan Derawan, Berau Regency, East Kalimantan province. The magnitude of the potential of biological resources of the high seas should be in balance by protecting the habitat of the biota ecosystem especially in Derawan Ecotourism. Habitat protection is essential for the survival of marine life marine life so greatly needs to be preserved in terms of clean-up in Derawan fella. Clean-up the beach or Coastal Clean-up is a internasioal activity developed in the coastal region to the sustainability and the protection of ecosystems. The activities of the coastal clean-up has been carried out in the area of ecotourism Derawan obtained 3 types of waste from households, trash and garbage from nature traveler. The overall total as many as $157 \mathrm{~kg}$ with the composition of the distribution type of the garbage comes from tourists amounted to $2 \mathrm{~kg}$ with a percentage of $1 \%$ then the distribution of the types of waste derived from the nature of $60 \mathrm{~kg}$, with the percentage of $38 \%$ and then the distribution of the types of trash comes from citizens/households amounting to $95 \mathrm{~kg}$ with a percentage of $61 \%$.
\end{abstract}

Keywords: Coastal Clean-Up, Junk, Derawan Island, East Borneo

\section{PENDAhUluAN}

Negara Indonesia memiliki tingkat keanekaragaman spesies fauna tinggi terdiri dari tiga kawasan fauna yaitu Region Oriental di sebelah barat, Region Australian di timur dan Kawasan Wallacea
(Atmoko, 2010). Keanekargaman hayati fauna yang berada di habitat teretrsial dan akuatika yang memiliki habitat sesuai ecological preference salah satunya adalah kawasan Wisata Pulau Derawan. Yang terletak di Kecamatan Pulauan Derawan, 
Kabupaten Berau, Provinsi Kalimantan Timur.

Derawan merupakan daerah ekowisata yang banyak di kunjungi oleh wisatawan baik lokal maupun mancanegara. Kepulawan Derawan menjadi tujuan utama destinasi wisata karena terdiri dari beberapa pulau, dimana setiap pulaunya memiliki keunikan dan keindahan yang luar biasa.

Obyek wisata ini berada pada wilayah Kabupaten Berau Kalimantan Timur, terletak persis pada sisi bagian paling timur provinsi Kalimantan Timur dan berbatasan langsung dengan laut Sulawesi. Kepulauan ini terdiri dari gabungan beberapa pulau pulau kecil yaitu: Pulau Derawan, Pulau Maratua, Pulau Kakaban, dan Pulau Sangalaki.

Kepulauan Derawan adalah ekoregion laut Sulu-Sulawesi yang melintasi Indonesia, Malaysia, dan Filipina. Ekoregion ini terletak di pusat kawasan segitiga karang dunia dengan keanekaragaman hayati karang tertinggi di dunia. Segitiga karang dunia ini disebut juga the coral triangle, karena menjadi episenter kehidupan laut yang memiliki keragaman biota laut. Terumbu karang di kawasan ini mencakup 53 persen terumbu karang dunia. Bahkan berdasarkan penelitian yang dikembangkan, Kepulauan Derawan merupakan salah satu multi countries feeding ground yang terpenting di dunia (Dinas Kebudayaan dan Pariwisata Kabupaten Berau, 2016).

Target kegiatan Coastal Clean-Up adalah Mahasiswa Universitas Borneo Tarakan. Kegiatan Coastal Clean-Up bermaksud :

1. Membangkitkan pengetahuan, kesadaran dan kepedulian Mahasiswa
(Halaman 37-43)

akan pentingnya menjaga ekosistem di wilayah wisata Pulau Derawan. Selain itu, kegiatan Coastal Clean-Up diharapkan mampu meningkatkan potensi ekowisata Pulau Derawan dengan menarik animo masyarakat untuk berkunjung. Tingginya animo masayaraat untuk berkunjung akan meningkatkan sumber pendapatan daerah pada sektor pariwisata namun tetap mengedepankan wisata sehat dengan tidak membuang sampah disembarang tempat. Kegiatan Coastal Clean-Up sangat memberikan kesempatan bagi Mahasiswa UBT sebagai relawan dari Kota Tarakan guna berpartisipasi dalam kampanye kebersihan di Pulau Derawan ini.

2. Sebagai salah satu bentuk dukungan terhadap dunia mengenai kepedulian terhadap Coastal Clean-Up untuk menjadikan salah satu contoh dalam menjaga ekosistem habitat vital dari biota akuatik yang berada di kawasan wisata Pulau Derawan.

3. Sebagai salah satu kegiatan dalam membangkitkan gairah Mahasiswa dalam semangat bersih-bersih yang merupakan penggalakan dalam program dunia agar memberikan kepedulian dan kesadaran akan lingkungan di sekitarnya karena berdampak terhadap lingkungan dan kesehatan di sekitarnya.

4. Sebagai salah satu produk dalam bentuk hasil nilai estetika alamiah di kawasan ekowisata di Pulau Derawan, Kabupaten Berau, Kalimantan Timur.

5. Sebagai salah satu daerah percontohan dalam kepedulian terhadap bersih (Coastal Clean-Up) di Kawasan Ekowisata. 
6. Menjadikan Mahasiswa sebagai salah satu yang mendukung kebersihan lingkungan di daerah Coastal Clean-Up yang merupakan bagian program dunia dalam menciptakan kawasan yang bersih.

Luaran yang diharapkan dengan adanya kegiatan Coastal Clean-Up diantaranya adalah sebagai berikut :

1. Peningkatan pengetahuan, kesadaran dan kepedulian Mahasiswa UBT untuk pro-aktif dalam upaya menjaga kelestarian ekosistem wilayah Pulau Derawan.

2. Menggalakkan program Coastal Clean-Up rutin di Mahasiswa dalam upaya mendukung pelestarian ekosistem di Pulau Derawan, Kabupaten Berau, Kalimantan Timur.

3. Mengetahui berbagai macam jenis sampah yang terdapat di kawasan Pulau Derawan, Kabupaten Berau, Kalimantan Timur.

4. Di harapkan adanya program pengabdian masyarakat selanjutnya dalam pengelolaan sampah di kawasan Ekowisata Pulau Derawan, Kabupaten Berau, Kalimantan Timur.

\section{METODE}

Kegiatan bersih pantai (Coastal Clean$U p$ ) merupakan bagian dari upaya masyarakat internasional untuk peduli terhadap kebersihan wilayah lingkungan pesisir. Di kalangan internasional kegiatan Coastal Clean-Up melibatkan para relawan untuk melakukan kegiatan bersih pantai dengan metode survai, biasanya dilakukan dalam periode yang bersamaan atau serentak (Awaluddin, 2011). Masyarakat dunia mengenal kegiatan bersih pantai sebagai International Coastal
(Halaman 37-43)

Clean-Up (ICC) yang dilakukan secara serentak dan rutin setiap tahunnya di berbagai pesisir pantai di seluruh dunia.

International Coastal Clean-Up merupakan konsep kegiatan yang efektif untuk meningkatkan kesadaran masyarakat terhadap pencemaran pesisir pantai melalui pengalaman langsung survai dan mengambil sampah secara langsung (Ohkura dan Kojima, 2007). Berdasarkan Ohkura dan Kojima (2007), kegiatan tersebut dapat memberikan tantangan dan pengetahuan para peserta akan beberapa hal berikut :

1. Sumber pencemaran pesisir pantai berasal dari sampah yang dihasilkan dari kegiatan masyarakat sehari-hari yang dibuang melalui sungai atau saluran lainnya.

2. Setiap orang menghasilkan sampah yang mudah terlihat dan sudah dianggap maklum.

3. Solusi yang terbaik adalah mengembangkan komunitas masyarakat yang peduli dan handal untuk menanggulangi pencemaran wilayah pesisir serta mengembangkan masyarakat untuk memiliki orientasi daur ulang.

Menurut Awaluddin (2011), ada beberapa hal utama yang harus menjadi perhatian dalam kegiatan ini,yakni :

1. Sebelum Kegiatan

a. Koordinator kegiatan melakukan survai daerah yang tepat untuk dijadikan lokasi kegiatan.

b. Memperhatikan bahan-bahan logistik yang akan diperlukan dalam pelaksanaan kegiatan seperti: sarung tangan, plastik sampah, alat tulis kantor dan pendukung lainnya. 
$\begin{array}{rrr}\text { Melakukan kontak dengan } \\ \text { pemerintah } & \text { terkait } & \text { untuk }\end{array}$ penanganan sementara dan akhir hasil sampah yang dikumpulkan.

c. Memperhatikan barang-barang yang dapat di daur ulang, seperti kertas, plastik, kaca.

d. Merencanakan penanganan untuk bahan-bahan berbahaya, seperti lateks, jarum suntik dan tampon agar aman dari jangkauan anakanak.

e. Menyiapkan alat timbangan untuk mengukur berat sampah yang dihasilkan.

f. Menyiapkan alat pertolongan pertama pada kecelakaan $(\mathrm{P} 3 \mathrm{~K})$ di lokasi kegiatan.

g. Melakukan simulasi atau penjelasan tentang teknis kegiatan kepada para peserta, serta menunjukkan cara mengisi form data.

h. Melakukan pembagian kelompok.

2. Selama Kegiatan

a. Menyiapkan tempat-tempat cekpoint untuk para peserta, termasuk semua kebutuhan logistik yang diperlukan, termasuk berikan data untuk diisi selama kegiatan.

b. Menyiapkan zonasi atau area yang harus dibersihkan. Setiap koordinator kelompok harus mengetahui lokasi tersebut.

c. Menyampaikan kepada peserta untuk mengembalikan data setelah kegiatan berakhir.

d. Melakukan pengambilan sampah seperti yang tercantum dalam data.
e. Memberikan apresiasi terhadap para peserta dalam berbagai bentuk, seperti stiker/kaos.

3. Setelah Kegiatan

a. Mengembalikan data kepada kooordinator untuk kemudian dilakukan analisis bersama dinas terkait atau Lembaga Swadaya Masyarakat (LSM) yang bergerak dibidangnya.

b. Memberikan apresiasi terhadap para peserta dapat berupa kartu ucapan terima kasih, sertifikat dan atau yang sejenis lainnya.

\section{HASIL DAN PEMBAHASAN}

Program coastal clean up dilakukan pada tanggal 22 April 2017. Kegiatan aksi coastal clean up di seluruh Pulau Derawan. Fungsi dari pengabdian kepada masyarakat terkait coastal clean up yaitu untuk memberikan kesadaran terhadap pribadi masing-masing masyarakat mengenai manfaat dan pentingnya kebersihan pantai bagi masyarakat itu sendiri ataupun bagi para wisatawan selain itu pula dapat pula menaikkan pendapatan perkapita bagi masyarakat setempat.

Berdasarkan hasil wawancara dan data kuisioner sebagian masyarakat pesisir Pantai Amal belum mengetahui secara detail konsep kegiatan coastal clean up yang digagas oleh masyarakat pesisir dunia lewat program International coastal clean up. Faktanya, secara teknis masyarakat Pulau Derawan hanya sekedar mengetahui kegiatan kerja bakti yang merupakan bagian dari kegiatan warga setempat. Namun, pemahaman masyarakat Pantai Amal masih sebatas membakar sampah yang telah dikumpulkan dengan tidak memilah antara sampah organik 
maupun anorganik. Hal ini sesuai dengan hasil penelitian Awaluddin (2011) yang menunjukkan pemahaman masyarakat di Pantai Sindangkerta terkait cara bersih bersih pantai dengan membakar sampah yang telah dikumpulkan.

Kegiatan coastal cleanup yang dilakukan di Pulaau Derawan dengan melibatkan peran aktif Mahasiswa dan Masyarakat mengacu ke konsep ICC sekaligus meningkatkan kesadaran masyarakat untuk menjaga ekosistem Pulau Derawan dan sekitarnya, mengingat bahaya abrasi terus semakin mengancam.

Selama kegiatan coastal clean up berlangsung,total keseluruhan Mahasiswa yang terlibat sebanyak 288 Mahasiswa. Kelompok mahasiswa yang ikut terlibat terdiri dari Mahasiswa Fakultas Hukum Lokal B 34 orang dan Lokal C 20 orang, Mahasiswa Fakultas Pertanian C 36 orang, Mahasiswa Fakultas Ekonomi Prodi Manajemen A 34 orang. Fakultas Keguruan dan Ilmu Pendidikan terdiri dari beberapa prodi yaitu Prodi PGSD A 34 orang, PGSD B 39 orang, Bhs Inggris A 36 orang, Bhs Inggris B 23 orang, Bimbingan Konseling B 32 orang. Presentasi Mahasiswa dapat dilihat pada Gambar 1.

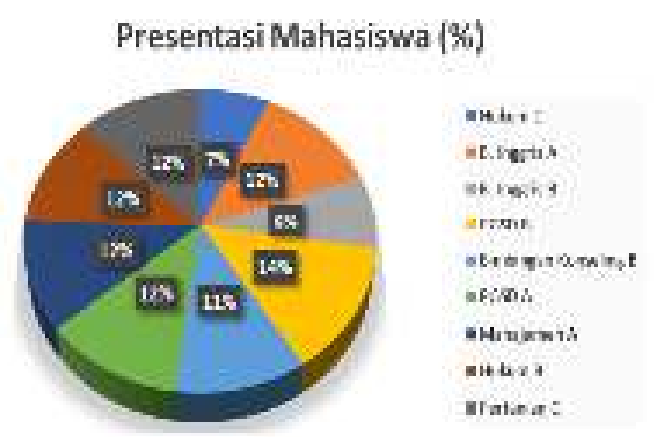

Gambar 1. Presentasi Mahasiswa yang hadir pada coastal clean up di Pulau Derawan
(Halaman 37-43)

Pelaksanaan kegiatan coastal clean-up di kawasan ekowisata Pesisir pulau Derawan Kalimantan Timur yang di ikuti oleh mahasiswa/i yang mengikuti kuliah lapang mata kuliah Pengantar Ekologi Laut Tropis jurusan Agribisnis Tahun 2017 yang dilaksanakan pada tanggal 22 April 2017, bertempat di pesisir pulau Derawan.

Hasil pelaksanaan teknis kegiatan coastal clean-up didapatkan tiga jenis sampah yang telah di identifikasi sesuai dengan yang didapat di lapangan. Ketiga jenis sampah yang terdapat di pesisir pulau Derawan berasal dari sampah dari rumah tangga sebanyak $95 \mathrm{~kg}$, sampah dari alam sebanyak $60 \mathrm{~kg}$ dan sampah dari wisatawan sebanyak $2 \mathrm{~kg}$.

Pada tabel di bawah ini adalah distribusi jenis sampah, berat sampah dan persentase jenisnya sebagai berikut ini :

Tabel 2. Distribusi Jenis, Berat dan Persentase Sampah

\begin{tabular}{|c|c|c|c|}
\hline No & Jenis Sampah & $\begin{array}{c}\text { Berat Sampah } \\
\text { Satuan (kg) }\end{array}$ & $\begin{array}{c}\text { Persentase } \\
(\%)\end{array}$ \\
\hline 1 & $\begin{array}{l}\text { Sampah dari } \\
\text { warga / rumah } \\
\text { tangga }\end{array}$ & $95 \mathrm{~kg}$ & $61 \%$ \\
\hline 2 & Sampah dari alam & $60 \mathrm{~kg}$ & $38 \%$ \\
\hline 3 & $\begin{array}{l}\text { Sampah dari } \\
\text { wisatawan }\end{array}$ & $2 \mathrm{~kg}$ & $1 \%$ \\
\hline & TOTAL & $157 \mathrm{~kg}$ & $100 \%$ \\
\hline
\end{tabular}

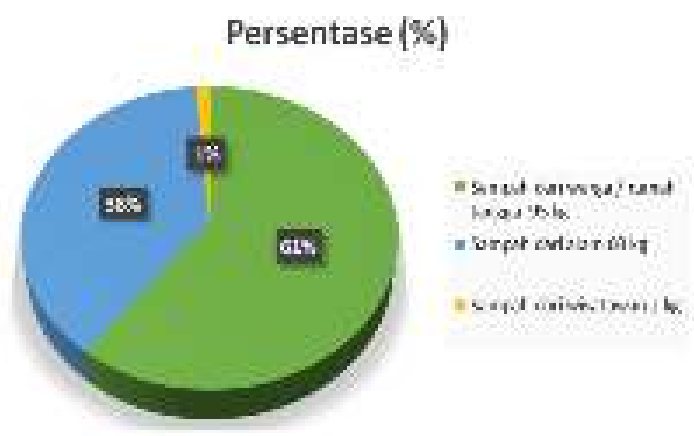

Gambar 2. Komposisi Berat dan Jenis Sampah 
Sampah dari hasil bersih pantai sepanjang Kawasan Ekowisata Pulau Derawan didapatkan sampah sebanyak 157 kg dengan komposisi distribusi jenis sampah berasal dari wisatawan sebesar 2 $\mathrm{kg}$ dengan persentase sebesar $1 \%$ kemudian distribusi jenis sampah berasal dari alam sebesar $60 \mathrm{~kg}$ dengan persentase sebesar $38 \%$ kemudian distribusi jenis sampah berasal dari warga/rumah tangga sebesar $95 \mathrm{~kg}$ dengan persentase sebesar $61 \%$. Banyak masyarakat berminat dan tertarik dengan kegiatan ini karena merupakan salah satu bagian dari kesadaran dalam diri dalam menjaga lingkungan di sekitarnya.

Persentase dan berat sampah yang didapatkan menggambarkan keadaan Pulau Derwan yang di kelilingi oleh bahan pencemar. Akumulasi bahan pencemar secara terus menerus dapat mengamcam keberlangsungan hidup biota disekitar pantai dan di badan perairan sendiri. selain itu, akumulasi bahan pencemar yang berasal dari berbagai sumber di Pantai Amal menambah panjang cerita abrasi yang sudah terjadi selama bertahun-tahun kebelakang. Menurut Dahuri et al (1996), Peningkatan kesadaran lingkungan hidup merupakan bagian dari pendekatan pembangunan masyarakat pantai. Banyaknya jumlah bahan pencemar di kawasan pantai sangat dikhawatirkan akan merusak tidak hanya ekosistem di sekitarnya tetapi juga kualitas kesehatan warga pantai yang bersangkutan (Awaluddin, 2011).

\section{KESIMPULAN}

Pengabdian kepada masyarakat di Kawasan Ekowisata Pulau Derawan Kabupaten Berau, Provinsi Kalimantan
VOLUME 2 NOMOR 2 DESEMBER 2018 (Halaman 37-43

Timur. didapatkan 3 jenis sampah yang di pisahkan yaitu sampah dari masyarakat/warga, sampah dari alam dan sampah dari wisatawan. Total keseluruhan sebanyak $157 \mathrm{~kg}$ dengan komposisi distribusi jenis sampah berasal dari wisatawan sebesar $2 \mathrm{~kg}$ dengan persentase sebesar $1 \%$ kemudian distribusi jenis sampah berasal dari alam sebesar $60 \mathrm{~kg}$ dengan persentase sebesar $38 \%$ kemudian distribusi jenis sampah berasal dari warga/rumah tangga sebesar $95 \mathrm{~kg}$ dengan persentase sebesar $61 \%$. Banyak masyarakat berminat dan tertarik dengan kegiatan ini karena merupakan salah satu bagian dari kesadaran dalam diri dalam menjaga lingkungan di sekitarnya.

\section{DAFTAR RUJUKAN}

Atmoko, T. 2010. Beberapa Aspek Bioekologi Bekantan (Nasalis larvatus Wurmb).

Awaluddin, Y.M. 2011. Introduksi Konsep Bersih Pantai (Coastal Clean-Up) Di Pantai Sindangkerta, Kecamatan Cipatujah, Kabupaten Tasikmalaya. Jurnal Harpodon. Volume 4. No. 2.

Bismark, M. Biologi Konservasi Bekantan Nasalis varkatus. SA. Siran, A. Syarief Mukhtar, T. Setyawati (Ed).

Departemen Kehutanan. Pusat Penelitian dan Pengembangan Hutan dan Konservasi Alam. Bogor. ISBN 978-979-3145-42-6.

Handaka, AA., I. Riyantini, M.Y. Awaluddin. 2007. Kepedulian Masyarakat Terhadap pencemaran di wilayah pesisir Pameungpeuk Kabupaten Garut. Jurnal Akuatika. FPIK Unpad.

Ohkura, Y. and Kojima, A., 2007. International Coastal Clean-Up 
Campaign Coordinated by JEAN in Japan Present state and future prospects. The $2^{\text {nd }}$ NOWPAP Workshop on Marine Litter. 28-29 March.

Ocean Concervancy. 2011. Tracking trash 25 years of action for the Ocean. Organisation Report. 43pp.
Salim, G dan Febrinaldy R. 2017. Introduksi Program Coastal Clean-Up di Pantai Amal Kecamatan Tarakan Timur Kota Tarakan. Laporan Akhir Kegiatan Pengabdian kepada Masyarakat yang berasal dari DIPA Universitas Borneo Tarakan. 42 Halaman. Tidak di publikasikan. 